\title{
Exploring Postmethod Pedagogy in Teaching English as Second Language in South African Higher Education
}

\author{
Hlaviso A. Motlhaka \\ University of the Free State, School of Social Sciences and Language Education, RSA \\ mothakaha@ufs.ac.za
}

\section{Doi:10.5901/mjss.2015.v6n1p517}

\begin{abstract}
This article investigated the use postmethod pedagogy for professional growth of lecturers to improve ESL students' English proficiency using qualitative approach with open-ended questionnaires and in-depth interviews to collect data. The research population of this study included twelve ESL lecturers (six females and six males) in the faculty of education at three institutions of higher education five to twenty years of teaching experience. The study found that postmethod pedagogy recognises the need for inclusivity of students and the empowerment of lecturers to ensure that what happens in the classroom is making a difference outside the classroom. The results suggest that lecturers recognize their own powers as great sources in creating methods for their professional growth and creation of a meaningful learning environment. This study recommends that lecturers should consider student choices and initiative as a fundamental factor for successful ESL learning and teaching, while striving for professional growth.
\end{abstract}

Keywords: Postmethod pedagogy, critical pedagogy, reflective practice in action, transformative intellectual, student autonomy.

\section{Introduction and Background}

Postmethod pedagogy is inclusive by considering the reality of the lives of English as Second Language (ESL) students and those of lecturers as a significant tool that results in positive outcomes of teaching and learning. It is primarily concerned with the real life communication in the L2 classroom that lead to more engaged students with optimal opportunities to enhance their fluency in achieving their fullest potential beyond the classroom (Motlhaka \& Wadesango, 2014). It also does not mean the end of conventional teaching methods but it can be regarded as an alternative to the deficiencies experienced by these methods (Can, 2008, Khany \& Darabi, 2014). According to Kumaravadivelu (2003, 2006), postmethod pedagogy is the optimal way of teaching English to reshape the character and content of $L 2$ teaching, teacher education and classroom activities. It therefore makes ESL lecturers to be aware of and justify their teaching process based on their teaching experiences and knowledge of methods to construct their own methods as evaluators, observers, critical thinkers, theorizers and ESL practitioners. In this paradigm, lecturers are encouraged to explore what works and what does not work using what Brown (2007) calls an enlightened and eclectic method to deal with ESL students' language deficiency. For instance, lecturers can use Kumaravadivelu's three types of interaction in ESL classroom: (1) interaction as textual activity where students modify their linguistic resources to maximize the chances of mutual understanding and reduce communication breakdown; (2) interaction as an interpersonal activity which helps students to negotiate and co-construct meanings of the utterances; and (3) interaction as an ideational activity which fits students' linguistic and discoursal resources with social, cultural and political context. These three types of interaction could help lecturers to consider communicative and interactional competences in designing ESL syllabi and teaching materials. In order for lecturers to effectively adopt Kumaravadivelu's three types of interaction in ESL classroom, they should theorize what they practice and practice what they theorize. This stance provides lecturers with a theoretical understanding of language pedagogy which is socially-realistic and contextually-sensitive to ESL teaching. This also discourages lecturers to rely on prescriptive approaches and methods from established authorities, but explore their own teaching approaches and methods to understand their strengths and limitations so that they can appropriately adapt their teaching procedures (Saville-Troike, 2006). In this case, lecturers are given a voice and audience to listen to their voices in formulating their own philosophies of teaching and learning for an inclusiveness and empowerment them with the potential for many desirable outcomes.

The postmethod discourse underpins Kumaravadivelu's three principles of language teaching which address aspects of practice (pedagogy of practicality), context (pedagogy of particularity) and empowerment (pedagogy of 
possibility). These three principles aim to provide a comprehensive context for language teaching for social engagement and political accountability. Lecturers in postmethod paradigm are expected to be confident and competent whenever practicing their profession for social transformation and improving the society by considering the life history of their students when designing ESL learning activities and materials. Postmethod pedagogy is therefore linked with critical pedagogy which advocates social justice and social transformation through education. In language teaching, critical practice is "about connecting the word with the world with a belief that what happens in the classroom should end up making a difference outside the classroom" (Akbari, 2008: 644). The postmethod condition reforms the character and content of L2 teaching, teacher education and classroom research to seek an open-ended and coherent framework centred around current theoretical, empirical and pedagogical insights that help lecturers to theorize from practice and practice what they theorize to attain several possibilities of teaching ESL. It can therefore be concluded that postmethod pedagogy signifies lecturer autonomy. It also argued that postmethod pedagogy signifies student-autonomy when intertwined with critical pedagogy as it seeks to create democratic classroom and authentic learning experience that contribute to existing curricula (Mothaka \& Wadesango, 2014). With this in mind, reflective practice serves a means to improve classroom practices for lecturers to consider alternative teaching methods to meet students' learning goals and their professional growth/development. Professional development through reflective practice gives lecturers opportunities to examine their abilities, values; and mostly their successes and failures in a realistic context in addressing students' learning needs (Park, Widodo \& Cirocki, 2010). After all, reflective practice in action coupled with postmethod pedagogy allows lecturers to continuously think about their professional practice in relation to what they call "unlearning", "learning", reflection and "evaluation" and impact they have on their students to validate their students' ability to think critically about their education situation.

\section{Theoretical Framework}

This study adopts reflective practice in action as a theoretical framework because it is rounded on the theory that advocates learning through and from experience towards gaining new insights of self and professional practice. This theory is not only concern with the professional growth of lecturers but also with students' performance, as it is conducive to students' learning of what to do in the world and holds the potential for expanding students' understanding of what is being taught (Ottesen, 2007). For this reason, reflective practice in action encourages lecturers to reflect on their teaching experiences for practical suggestions to improve and energize their professional growth, teaching methods, and classroom strategies.

\section{Statement of the Problem}

English language teaching in South Africa has gained a special status during colonization, apartheid and post-apartheid because it is integral to academic achievement, career development and functioning in a multilingual society. During postapartheid, the South African education policy adopted Outcomes Based Education (OBE) and now the Curriculum and Assessment Policy Statement (CAPS) for adapting and redefining the teaching of ESL in higher education institutions for inclusivity and addressing the learning needs of students beyond the classroom. However, both the Outcomes Based Education (OBE) and the Curriculum and Assessment Policy Statement (CAPS) prescribe to teachers how to teach English, particularly, the use of text-based, communicative, integrated and process orientated approach. In this case, CAPS does not regard teachers as individuals who are capable of developing their own teaching strategies informed by their teaching and learning philosophies. In any case, students continue to have a Limited English Proficiency (LEP) which hinders their true potential to succeed in higher education due to the overwhelming use of English as the Language of Teaching and Learning in most universities across the country. The current study intended to accustom and empower lecturers to the idea of change to contextualize their class practice and liberates them from the limitations enforced by prescribed teaching methods for their professional growth and meeting the learning needs of their students through postmethod pedagogy.

\section{Research Questions}

The main research questions in this study were:

- How does postmethod pedagogy enhance lecturers' professional growth and teaching practice?

- How does the practice of postmethod pedagogy improve students' ESL proficiency? 


\section{Aim of the Study}

Due to the limitations and enforced teaching methods to ESL lecturers through prescribed teaching methods in the Curriculum and Assessment Policy Statement (CAPS), and the continuous and overwhelming Limited English Proficiency among ESL students, this study seeks to explore postmethod pedagogy for professional growth and teaching practices of lecturers to improve ESL students' English proficiency.

\section{Objectives of the Study}

In order to achieve the aim of this study, the following objectives have been formulated:

- To enhance ESL lecturers' professional growth and teaching practice through postmethod pedagogy.

- To improve students' English proficiency and learning through the application of postmethod pedagogy in the classroom.

\section{Research Methodology}

Qualitative research approach was used to get in depth understanding of individuals and events in their natural state. According to Silverman (2013) qualitative research helps the researcher to explore the participants' experiences and understanding of these experiences in which lecturers were asked questions to answer regarding the use of postmothed pedagogy. Data was collected through the use of open-ended questionnaires and in-depth interviews because the researcher wanted to gather in-depth information about lecturers' views on the use of postmethod pedagogy.

\subsection{Research design}

This study used phenomenological research design where the researcher forms part of the day-to-day life of his/her population in gathering data (Creswell, 2012). The phenomenological research paradigm is appropriate to address meanings and perspectives of research participants to understand how the everyday, inter-subjective world is constituted from the participants' perspective on the use of postmethod pedagogy. The researcher in this study works at one of the institutions where he collected data and this gave him the opportunity to interact with lecturers in order to gather information on the use of postmethod paradigm.

\subsection{Participants}

The participants of this study included twelve ESL lecturers (six females and six males) in the faculty of education at three institutions of higher learning. The age of participants in this study ranged from twenty-eight to fifty years old. Participants are having five to twenty years of teaching experience. They were assured that the results of this study would be confidential and those who were willing to participate in this study were asked to participate. The participants were selected on the basis of convenience sampling method.

\subsection{Data collection and instruments}

Data collection in qualitative research is collected in its natural setting to make information richer with deeper insight into the phenomenon under study. Information was gathered through the use of open-ended questionnaires and in-depth interviews of lecturers. All participants were given open-ended questionnaires and volunteered to participate in the interview sessions to explore the meaning of that experience for lecturers and ask them to describe their everyday lived experience through the use postmethod pedagogy.

\subsection{Data analysis}

The analysis of data aims to make sense and meaning of data by consolidating, reducing and interpreting what has been said and read by the researcher. Data collected from taped recorded interviews was transcribed verbatim and summarizing the salient aspects. The understanding and meaning of data was organized in accordance of bracketing method that allows the emergence of themes that involve the following steps (Tufford \& Newman, 2010):

- Locate key phrases and statements that speak directly to the phenomenon in question. 
- Interpret the meanings of these phrases, as an informed reader.

- Obtain the participants' interpretations of these phrases.

- Inspect these meanings for what they reveal about the essential recurring features of the phenomenon being studied.

- Offer a tentative statement, or definition, of the phenomenon in terms of the essential recurring features identified.

\section{Results and Discussion}

The purpose of this study was to explore postmethod pedagogy for professional growth and teaching practices of lecturers to improve ESL students' English proficiency. The results of this study may serve as a good alternative to the deficiencies experiences through the use of prescribed/conventional methods and a meaningful way of L2 teaching and learning. The discussion of the results of this study is presented through the category of professional growth and teaching practices of lecturers, and improvement of English proficiency of students with the following sub-categories: The role of lecturers as transformative intellectuals, maximising learning opportunity, promoting student autonomy, contextualizing linguistic input, valuing adventure learning and acknowledging individual cultures.

\subsection{The role of lecturers as transformative intellectuals.}

The term transformative intellectual was coined by Henry Giroux (1988) who believed that lecturers possess the knowledge, skills, values and attitudes to question, understand, interrogate and act as change agents of structural inequities in their place of employment. Lecturers regard learning and teaching as a transformative process in which they learn from their students in order to improve their professional practices and values to address students' learning needs. They strive to help students be knowledgeable, critical and brave enough to find out new and develop them into active citizens and engage in social change. Therefore, lecturers through critical pedagogy and postmethod pedagogy are involved in a process of knowledge appropriation and application by being critically aware of their roles in the classroom for their professional growth and creation of a meaningful learning environment. In this case, lecturers need to ensure acceptance for all students in the classroom by: (1) choosing learning materials to represent all groups of students, (2) talking and celebrating cultural and ethnic differences, (3) ensuring that learning activities are designed for a variety of abilities and (4) ensuring that all students are protected from name-calling or other forms of abusive language.

Lecturers should therefore be dedicated to the creation and implementation of forms of knowledge, curricula and syllabi that are relevant to address their needs, wants and situations, and those of their students (Kumaravadivelu, 2006). For this reason, lecturers view postmethod pedagogy as a mechanism for maximising learning opportunities in the classroom and as a means for professional growth beyond the classroom. This could be achieved when lecturers cultivate and extend research skills that explore problems they posed about their life in and outside the classroom by responding and monitoring its effects on themselves and their students. In essence, lecturers conceptualize classroom techniques that encourage introspection, self-reflection and instil a sense of ownership of their own education and those of their students. After all, lecturers should go beyond the professional theories transmitted to them through formal teacher education programmes in order to conceive and construct their personal theory of teaching for professional growth and to maximize learning opportunities.

\subsection{Maximising learning opportunities}

Creativity and the use of various teaching methods in the ESL classroom through postmethod paradigm are found to be significant in maximising learning opportunities for students. The study found that learning opportunities in the classroom can be created by lecturers as well as students through negotiated syllabus rather than relying on a predetermined syllabus or a prescribed textbook. This provides students with active involvement in the shared tasks of developing a syllabus via the process of negotiating with the lecturer. For instance, the lecturer writes learning activities and parts of the course on the board wherein students work in small groups to discuss what should be removed from the list and what should be added to it. This approach in language teaching gives priority to the recognition students' needs within a course with students play a central role in determining how language is taught and learned (Nation \& Macalister, 2010). It simply focuses on how the syllabus is made rather than what should be in it. The study also finds that this approach creates a high degree of interest, promotes high-level of thinking and gives students the confidence they need to be successful in learning ESL. Therefore, lecturers need to develop autonomy by integrating students' learning experience in class with 
real life and intervene where necessary to enable students to develop knowledge that they could use in real life for further learning of ESL beyond the classroom. This means that lecturers should create a learning environment that gives the opportunity to transform and instigate learning activities to suit students' learning styles and abilities guided by lecturers ' instructions. This efficient or resourceful learning environment with effective choices is characterized by students' responsibility towards their choice and proactive role. In this situation, students are capable of completing any chosen task; mostly on their own or with the minimum help from lecturers because they have a sense of ownership and accountability in pursuance and fulfilling their learning interests. In sum, it is imperative for lecturers to demonstrate willingness to utilize learning opportunities created by their students, and appreciate what students have to say.

\subsection{Promoting student autonomy}

Teaching method that contributes both to students' control over their own language learning process and develops their language proficiency is integral to postmethod pedagogy. This means that ESL students whose initiative and creativity are valued in the learning and teaching process become more motivated and competent as compared to those who do not have the same privilege. In this case, student autonomy is seen as an essential and optimal goal of enhance students' control over their language learning in relation to the students' goals, language learning process, tasks, student strategies and reflection on learning. An autonomous learning environment raises students' awareness of ways of identifying goals, specifying objectives, identifying resources and strategies needed to achieve goals and measuring their learning progress. This could be achieved if an ESL course provides students with preparation, practice, and feedback in which students would participate in the future. The potential for student autonomy increases students' learning awareness grows. Therefore, activities which prompt students to reflect on their learning aim to enhance students' insight into their learning processes. ESL students are becoming the source of information for class activities and the focus of curriculum design when lecturers show a strong positive attitude toward strategy instruction and provide rationale for strategy use. Lecturers should emphasize the goal of strategy instruction and work on students' learning strengths to sustain their current repertoires of learning strategies. At the heart of student autonomy lies the concept of choice within a curricular framework that is flexible and dynamic enough to allow for individual explorations.

\subsection{Contextualizing linguistic input}

Lecturers should not only pay attention to the language form, but also to the meaning and discourse of ESL in order to improve students' English proficiency. This means that words should be presented in sentences, while, sentences need to be practiced in meaningful contexts instead of being taught in isolated and disconnected elements. This study found that focus on form activities enhance students' engagement in real communication outside of the classroom through meaningful interactions by using their background knowledge of the target language (TL) to advance the learning of that language. This could be the reason why, in her studies, Yang (1999) found that students who assumed that learning the grammar and vocabulary were the essential parts of ESL were unlikely to search for or create opportunities to use the language, while focusing on meaning since those students would be more concentrated on perfecting the language rather than simply using the language as a means to communicate. The foundation of the meaning-focused approach is the belief that it is more beneficial for lecturers to promote the use of the language as much as possible, despite whether or not the students' language use is erroneous. Research about grammar has confirmed that L2 students-especially adults who successfully learned how to use the TL's grammar in the classroom -could not effectively apply these rules to real communication, but that sociolinguistic discourse and strategic competence should also be focused on in order to develop students' communicative competence. This affirms the need to focus more on conveying meaning than focusing on the formations of the language through grammar. To achieve this need, lecturers ought to provide students with activities in the classroom that enable them to use the target language for productive meaning-focused communication. However, there is always the risk that during a meaning-focused activity, students will focus naturally on the form-focused approaches such as grammar translation and cognitive methods.

According to Krashen, comprehensible input made available by lecturers to their students enables them to complete meaning-focused activities more successfully when students' current knowledge of the language (i) is incorporated with their perceived language achievement (i+1) (as cited in Kumaravadivelu, 2006). In this situation, students are given the opportunity to decide what to do in a given situation and how to solve emerging problems. The following conditions were proposed by Littlewood (1981) to promote language acquisition:

- Using activities that engage students in real communication and promote learning

- Utilizing activities where language is used in order to perform meaningful tasks and encourage learning 
- Instilling a passion for the language in order to motivate them in the learning process

\subsection{Valuing adventure learning}

Adventure learning is characterized by collaborative and inquiry-based learning approaches where students experience their learning in authentic situations with the purpose of discovering and discussing topics of interest to them. In other words, informal interaction between students, lecturers and other members of the community to discuss activities that directly affect students' real life can help them acquire fundamental skills that they could use outside the school to expand their diverse understanding and learning of a language (Moos \& Honkomp, 2011). Studies conducted by Donato and Adair-Hauck (1992) revealed that social settings create and shape opportunities for both learners and competent speakers of the $\mathrm{L} 2$ to communicate with each other, thereby maximizing learning potential. As a result, students' various learning experiences in realistic situations will make them feel more comfortable, autonomous and prepared to complete a given task without any hesitation. Indeed, an advantageous learning environment which values students' viewpoints and initiatives encourages students to be autonomous, determined and more constructive of language knowledge in adventure learning (Jones, Llacer-Arrastia \& Newbill, 2009). According to Jones, Llacer-Arrastia and Newbill autonomous learning is a motivating factor that provokes students' interest to construct new ESL knowledge in authentic situations. Therefore, through the realistic experiences in listening, students can confidently communicate their ideas in real situations. Another way to perform participatory pedagogy is through the problem-posing approach in which the students' lived experiences and issues faced in their community are brought to the classroom as a theme to be discussed. Discussions can also be generated by using authentic materials (e.g., pictures, videos, texts) and open-ended questions that lead students to compare experiences and make suggestions for improvements. Moreover, Norton (1995) found that participatory pedagogy can be used through classroom-based social research to help students acquire language through interviewing people, reporting and observation of how people use language for effective communication (as cited in Hall, 2002). For example, students record their language habits or language games with the target language and then use the data for discussions on language and language use. Students' experiences are used as the curricular base, which empowers them to invest in their own learning. Along similar lines, Kumaravadivelu (2006) claimed that social context is critical for comprehensible input in listening because it stimulates students' learning goals, motivation and ability to converse effectively in the community while at same time students strive to improve their proficiency levels.

\subsection{Acknowledging individual cultures}

If an individual culture is acknowledged, it is ultimately individual students who engage in that learning because of socially and culturally shaped differences in status and experience. The research of Souryasack and Lee (2007) suggested that when students are given the opportunity to express their own experiences, cultures and languages, they become curious and motivated to know and speak the target language. This leads to better outcomes in their ESL development compared to those students whose culture and language have been marginalized. Souryasack and Lee also argue that giving students opportunities to share their experiences, cultures and languages in the classroom can reduce the anxiety and fear that they may have in learning ESL because they have full control over the content that they share to the class. Feuer's (2009) claim is connected to Souryasack and Lee's (2007) findings when he said that acquisition of language in a social setting through friendship and discussion of ethnic identity and acceptable community values is regarded as an informal place of learning in which learning takes place experientially and voluntarily. Ethnic identity encompasses the manner in which a particular ethnic group identifies and distinguishes itself from others through common traditional and religious practice, language, food, preferences and clothing. These acceptable community values are core values in which a particular community shares its ideals and beliefs as the guiding principles for its existence. Another method to incorporate students' culture suggested by Chamberlin-Quinlisk, (2005) encourages the involvement of students in the intercultural partner projects where students get a chance to partner with other students who come from different cultural backgrounds to discuss their cultures and give presentations. In this example, students can write a reflective journal about their 24 intercultural experiences using the examples from the interaction with their partners. Scholars like Savignon (2002) and Nault (2006) claimed that cultural experience in interactive listening is a prerequisite for preparing ESL students for intercultural communication to proudly use their first language as they engage in cultural dialogue. In other words, cultural dialogue promotes diverse perspectives and practices, and develops students' acceptable moral values such as tolerance, respect and acceptance. This proves that cultural knowledge of the target language is essential to enhance students' understanding and learning of the target language. 


\section{Conclusion}

The findings of this study indicate that postmethod pedagogy recognises the need for inclusivity of students and the empowerment of lecturers to ensure that what happens in the classroom is making a difference outside the classroom. This allows lecturers to look at language and learning from a new perspective to optimize their potential as language practitioners. The finding suggests that lecturers should understand the confines of method in order to recognize their own powers as great sources in creating methods for their professional growth and creation of a meaningful learning environment. In order to achieve this, they should move beyond idealism to realism by using their experiences and knowledge to become researchers and language practitioners in appropriating knowledge and application. The study also finds that postmethod pedagogy recognizes students' learning needs within a course by transforming and instigating learning activities to suit students' learning styles and abilities guided by lecturers ' instructions. This means that students play a central role in determining how language is taught and learned. At the heart of student autonomy lies the concept of choice within a curricular framework that is flexible with potential for professional growth of lecturers. Furthermore, the study found that activities focusing on language form enhance students' engagement in real communication and meaningful interaction with the target language beyond the classroom walls if their background knowledge of the target language is considered. This type of teaching and learning paradigm is manifested by students' ability to be responsible and accountable for their own learning with the help from lecturers who are also critical of their own professional practice.

\section{Recommendations}

This study recommends that lecturers should consider student choices and initiative as a cornerstone or fundamental factor for successful ESL learning and teaching to maximize student motivation and learning opportunities, while striving for professional growth. This recommendation informed by Kumaravadivelu's three principles of language teaching which address aspects of practice (pedagogy of practicality), context (pedagogy of particularity) and empowerment (pedagogy of possibility).

\section{References}

Akbari, R. (2008). Postmethod Discourse and Practice, TESOL QUATERLY, 42(4)641-652.

Brown, H. D. (2007). Teaching by principles: An interactive approach to language pedagogy.

White Plains, NY: Pearson Education.

Can, N. (2008). Post-Method Pedagogy: Teacher Growth behind Walls. Proceedings of the 10th METU ELT Convention.

Chamberlin-Quinlisk, C. R. (2005). Across continent or across the street: Using local resources to cultivate intercultural awareness. Intercultural Education, 16(5), 469-479. doi: 10.1080/14675980500378532

Creswell, J.W. (2012). Qualitative inquiry and research design: Choosing among five approaches. Sage publications.

Donato, R., \& Adair-Hauk, B. (1992). Discourse perspectives on formal instruction. Language Awareness, 1, 74-78.

Feuer, A. (2009). School's out for the summer: Across-cultural comparison of second language learning in informal settings. International Journal of Bilingual Education and Bilingualism, 12(6), 651-665. doi:10.1080/13670050802549672

Hall, J. K. (2002). Teaching and researching: Language and culture . New York, NY: Pearson Education.

Jones, B. D., Llacer-Arrastia, S., \& Newbill, P. B. (2009). Motivating foreign language students using self-determination theory. Innovation in Language Learning and Teaching, 3(2), 171-189. doi: 10.1080/17501220802358210

Khany, R., \& Darabi, R. (2014). ELT in Iran: Reflection of the Principles-Based and Post-Method Pedagogy in Language Teaching. Procedia-Social and Behavioral Sciences, 98(2014), 908-916.

Kumaravadivelu, B. (2006). Understanding Language teaching: From method to Postmethod. London, UK: Lawrence Erlbaum Associates.

Kumaravadivelu, B. (2003). Critical language pedagogy: A postmethod perspective on English language teaching. World Englishes, 22(4), 539-550.

Littlewood, W. (1981). Communicative language teaching: An introduction. Cambridge, England: Cambridge University Press.

Moos, D. C., \& Honkomp, B. (2011). Adventure learning: Motivating students in a Minnesota middle school. Journal of Research on Technology in Education, 43(3), 231-252.

Mothaka, H. A., \& Wadesango, N. (2014). Freirean participatory approach: Developing interactive listening skills in the English as a Second Language (ESL) classroom. Mediterranean Journal of Social Sciences, 5(11), 101-107.

Nation, I.S.P., \& Macalister, J. (2010). Language curriculum design. New York; London: Routledge.

Nault, D. (2006). Going global: Rethinking culture teaching in ELT contexts. Language, Culture and Curriculum, 19(3), 314-328.

Ottesen, E. (2007). Reflection in teacher education, Reflective Practice: International and Multidisciplinary Perspectives, 8(1), 31-46, DOI: 10.1080/14623940601138899

Park, G., Widodo, P.H. \& Cirocki, A. (2010). Observation of Teaching: Bridging Theory and Practice through Research on Teaching. 
LINCOM Studies in Second Language Teaching. Muenchen: LINCOM GmbH.

Savignon, S. (2002). Communicative language teaching: Linguistic theory and classroom practice. In S. Savignon (Eds.), Interpreting communicative language teaching.

New Haven, CT: Yale University Press.

Saville-Troike, M. (2006). Introducing second language acquisition. Cambridge: Cambridge University Press.

Silverman, D. (2013). Doing qualitative research: A practical handbook. SAGE Publications Limited.

Souryasack, R., \& Lee, J. S. (2007). Drawing on students' experiences, cultures and language to develop English language writing: Perspectives from three Lao Heritage middle school students. Heritage Language Journal, 5(1), 79-96.

Tufford, L., \& Newman, P. (2010). Bracketing in Qualitative Research. Qualitative Social Work, 11(1), 80-96.

Yang, C. D. (1999, June). A selectionist theory of language development. In Proceedings of $37^{\text {th }}$ East Stroudsburg, PA: Association for Computational Linguistics, 429-435.

Meeting of the Association for Computational Linguistics. 